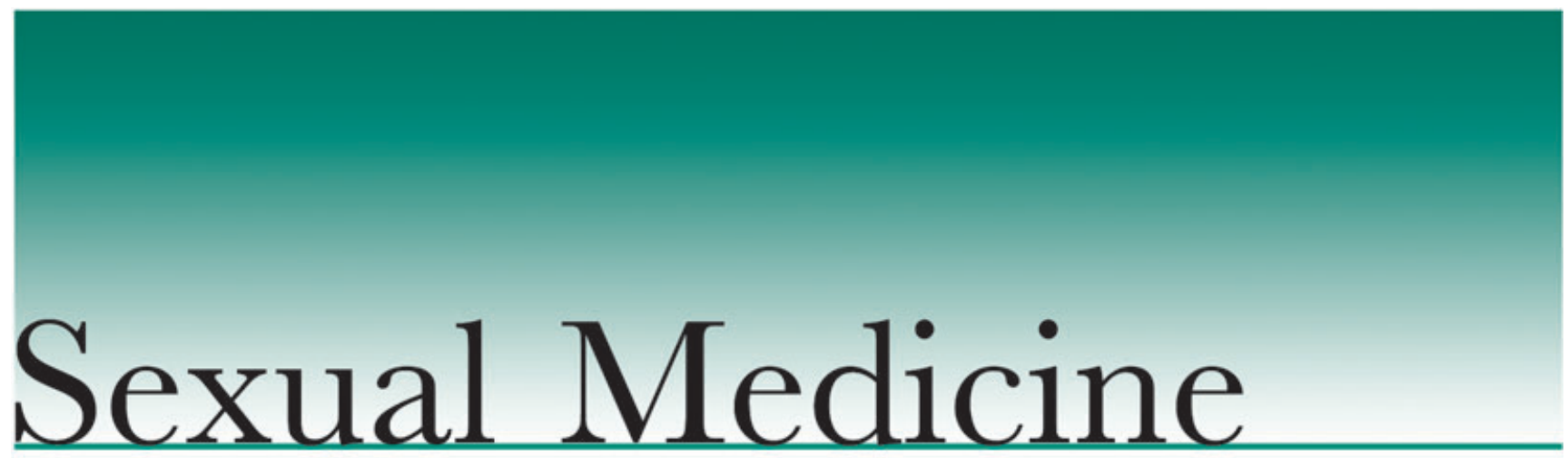

Associate Editor

Michael G. Wyllie

Editorial Board

Ian Eardley, UK

Jean Fourcroy, USA

Sidney Glina, Brazil

Julia Heiman, USA

Chris McMahon, Australia

Bob Millar, UK

Alvaro Morales, Canada

Michael Perelman, USA

Marcel Waldinger, Netherlands

\title{
Sexual problems and help-seeking behaviour in adults in the United Kingdom and continental Europe
}

Edson D. Moreira, Dale B. Glasser*, Alfredo Nicolosit, Fernanda G. Duarte and Clive Gingellキ for the GSSAB Investigators' Group

Gonçalo Moniz Research Center, Oswaldo Cruz Foundation, Salvador, Brazil, *Pfizer Inc, New York, NY, USA, +Department of Epidemiology and Medical Informatics, Institute of Biomedical, Technologies, National Research Council, Milano, Italy, and \#Bristol Urological Institute, Southmead Hospital, Bristol, UK Accepted for publication 13 September 2007

Study Type - Symptom prevalence study (prospective cohort study)

Level of Evidence $1 b$

\section{OBJECTIVES}

To study sexual activity, the prevalence of sexual dysfunction, and related help-seeking behaviour patterns among middle-aged and older people in the UK and Europe.

\section{SUBJECTS AND METHODS}

\section{A telephone survey was conducted using a structured questionnaire covering demographics, health, relationships, and sexual behaviour, attitudes and beliefs. In the UK, 1500 individuals completed the survey.}

RESULTS

Overall, $69 \%$ of men and $56 \%$ of women reported having sexual intercourse during the past year. The most common male sexual problems, i.e. early ejaculation (20\%) and erectile dysfunction (18\%), were more common in the UK than in other European regions. The most common female sexual problems, i.e. a lack of sexual interest (34\%) and a lack of pleasure in sex (25\%), were also more common in the UK than in other European regions. Only 26\% of men and 17\% of women had discussed their sexual problem(s) with a doctor.

\section{CONCLUSION}

Many people in the UK maintain sexual interest and activity into middle age and beyond. Although they experience sexual problems, few seek medical help. This might be because they do not perceive such problems as serious or sufficiently upsetting, and/or are not aware of available treatments.

\section{KEYWORDS}

epidemiology, health surveys, prevalence, sex, sexual disorders

\section{INTRODUCTION}

The recent growth in interest, among scientific and medical researchers and the general public, in the sexual problems of 
middle-aged and elderly people is due at least in part to the availability of new, effective oral treatments for male sexual dysfunction. Little is known about the frequency of sexual activity and the importance of sexual relationships among mature men and women, but the few studies that have examined sexuality in these age groups have reported that interest in sex persists into middle and older age [1-3].

The prevalence of erectile dysfunction (ED) has been extensively studied worldwide [4-10]; other male sexual problems, such as early ejaculation, have also received some attention $[6,7]$, but much less is known about sexual life and problems of mature and elderly women [11-13]. Furthermore, there are currently no recommendations about how men or women can manage or overcome their sexual problems, and there are no studies that allow a comparison of sexual behaviours and problems across many different countries.

The prevalence of sexual problems among middle-aged and elderly people has been studied in the UK and other European countries at national level [4-12], but differences in study design and definitions make valid cross-country comparison difficult. Several population studies have investigated the prevalence of the male sexual problems of ED and early ejaculation and their related risk factors $[4-7,9,10]$, but fewer studies of female sexual problems have been conducted in Europe $[11,12]$.

The Global Study of Sexual Attitudes and Behaviours (GSSAB) was a population survey of 27500 men and women aged $40-80$ years in 29 countries around the world $[14,15]$. Here we report the results from the respondents in the UK and compare the sexual behaviours, and the prevalence of sexual dysfunction and help-seeking patterns in this country, with those seen in other Northern and Southern European regions.

\section{SUBJECTS AND METHODS}

Using a random-digit dialling sampling design, computer-assisted telephone interviews were carried out in the UK and in other Northern (Austria, Belgium, Germany, Sweden) and Southern (France, Italy, Spain) European countries during 2001 and 2002. The respondents were randomly selected by asking for the man or woman in the

\begin{tabular}{|c|c|c|c|}
\hline Characteristic & Men & Women & TABLE 1 \\
\hline $\bar{N}$ & 750 & 750 & Selected characteristics of \\
\hline Age group, years & & & the study population, UK, \\
\hline $40-49$ & 25.6 & 24.9 & 2001-2002 (percentage; \\
\hline $50-59$ & 24.0 & 24.7 & age-standardized \\
\hline $60-69$ & 25.1 & 26.0 & prevalences) \\
\hline $70-80$ & 25.3 & 24.4 & \\
\hline \multicolumn{4}{|l|}{ Relationship status } \\
\hline Married or ongoing partnership & 62.1 & 57.1 & \\
\hline Divorced/separated without sex partner & 12.5 & 14.8 & \\
\hline Widowed without sex partner & 12.9 & 23.1 & \\
\hline Single without sex partner & 12.4 & 5.1 & \\
\hline Urban/suburban residential setting & 79.9 & 78.5 & \\
\hline \multicolumn{4}{|l|}{ Education } \\
\hline Primary school or less & 9.3 & 12.3 & \\
\hline Secondary/high school & 55.7 & 65.5 & \\
\hline At least some college & 35.0 & 22.2 & \\
\hline \multicolumn{4}{|l|}{ Household income } \\
\hline Low & 29.3 & 41.9 & \\
\hline Medium & 61.0 & 51.4 & \\
\hline High & 9.8 & 6.7 & \\
\hline \multicolumn{4}{|l|}{ Current employment status } \\
\hline Employed & 36.8 & 31.7 & \\
\hline Unemployed & 14.1 & 7.6 & \\
\hline Retired & 47.2 & 49.1 & \\
\hline Homemaker & 1.9 & 11.6 & \\
\hline \multicolumn{4}{|l|}{ Religion } \\
\hline Christian/Jew & 81.4 & 89.2 & \\
\hline Muslim & 2.7 & 0.9 & \\
\hline Buddhist or other Asian & 0.3 & 0.3 & \\
\hline Atheist & 0.0 & 0.0 & \\
\hline Not specified & 17.0 & 9.8 & \\
\hline Good to excellent general health* & 61.7 & 61.3 & *Self-reported good or \\
\hline Intercourse in the last 12 months & 68.5 & 56.0 & excellent general health (vs \\
\hline Intercourse more than once a week & 27.1 & 18.8 & fair or poor). \\
\hline
\end{tabular}

household aged 40-80 years. Verbal consent was obtained from all study participants and no personal identifying information was collected from any subject.

The questionnaire requested information on demographics, general health, relationships, and sexual behaviours, beliefs and attitudes. The subjects were asked if they had engaged in sexual intercourse during the previous year and the presence of sexual dysfunction was assessed by means of two sequential questions. The respondents were first asked whether they had ever experienced one or more of several sexual problems (listed below) for a period of $\geq 2$ months during the previous year, and those who answered positively were then asked to specify if they experienced it occasionally, sometimes or frequently.
We used logistic regression to investigate potential factors associated with selected sexual dysfunction. In these analyses, the presence of a sexual dysfunction was coded only for those respondents who reported experiencing the problem frequently or periodically, while those who indicated that they experienced the problem only occasionally were re-coded to indicate no sexual dysfunction.

The subjects who reported having a sexual problem were asked whether they had sought help or advice from a series of sources (see below). More than one source could be indicated.

The subjects with sexual problems who did not consult a physician were asked why they had not done so, and offered a list of 14 
TABLE 2 Age-standardized prevalence (\%,95\% Cl) of sexual problems in men and women by severity, 2001-2002

\begin{tabular}{|c|c|c|c|}
\hline Problem & UK & Northern Europe & Southern Europe \\
\hline \multicolumn{4}{|l|}{$\overline{M e n}$} \\
\hline Early ejaculation & $19.8(16.3,23.6)$ & $21.3(19.3,23.3)$ & $21.9(20.2,23.7)$ \\
\hline Occasional & $6.6(4.4,9.7)$ & $11.5(9.9,13.3)$ & $8.3(7.0,9.7)$ \\
\hline Periodic & $8.9(6.1,12.1)$ & $6.8(5.5,8.3)$ & $10.2(8.8,11.7)$ \\
\hline Frequent & $4.2(2.4,6.6)$ & $2.9(2.1,3.9)$ & $3.2(2.4,4.2)$ \\
\hline Erectile difficulties & $17.8(14.4,21.3)$ & $12.3(10.8,14.1)$ & $13.3(11.9,14.8)$ \\
\hline Occasional & $5.3(3.2,7.9)$ & $5.2(4.1,6.5)$ & $4.9(3.9,6.0)$ \\
\hline Periodic & $7.1(4.1,10.0)$ & $5.2(4.1,6.6)$ & $6.2(5.1,7.5)$ \\
\hline Frequent & $5.5(3.3,8.1)$ & $1.9(1.2,2.1)$ & $2.0(1.4,2.8)$ \\
\hline Lack of sexual interest & $15.1(11.9,18.5)$ & $12.0(10.5,13.7)$ & $13.3(11.9,14.8)$ \\
\hline Occasional & $4.3(2.4,6.6)$ & $6.1(4.8,7.5)$ & $6.7(5.6,8.0)$ \\
\hline Periodic & $6.0(3.8,8.8)$ & $4.1(3.0,5.2)$ & $5.2(4.2,6.4)$ \\
\hline Frequent & $4.8(2.9,7.5)$ & $1.9(1.2,2.7)$ & $1.4(0.9,2.1)$ \\
\hline Inability to reach orgasm & $13.7(10.8,17.2)$ & $7.9(6.6,9.3)$ & $12.5(11.2,14.0)$ \\
\hline Occasional & $3.2(1.6,5.4)$ & $4.1(3.1,5.4)$ & $5.3(4.3,6.5)$ \\
\hline Periodic & $7.1(4.6,10.0)$ & $2.7(1.9,3.7)$ & $5.3(4.3,6.5)$ \\
\hline Frequent & $3.4(1.8,5.7)$ & $1.0(0.5,1.7)$ & $1.7(1.1,2.4)$ \\
\hline Sex not pleasurable & $11.2(8.6,14.5)$ & $6.8(5.6,8.1)$ & $9.2(8.0,10.5)$ \\
\hline Occasional & $3.4(2.0,5.5)$ & $3.2(2.4,4.1)$ & $4.0(3.2,4.9)$ \\
\hline Periodic & $4.8(3.0,7.0)$ & $2.0(1.4,2.8)$ & $3.7(2.9,4.6)$ \\
\hline Frequent & $3.0(1.7,5.0)$ & $1.5(0.9,2.2)$ & $1.4(0.9,2.0)$ \\
\hline Pain during sex & $2.9(1.6,4.8)$ & $3.0(2.2,3.9)$ & $4.4(3.6,5.4)$ \\
\hline Occasional & $0.5(0.1,1.8)$ & $1.8(1.2,2.5)$ & $2.0(1.4,2.7)$ \\
\hline Periodic & $1.6(0.7,3.2)$ & $1.0(0.6,1.6)$ & $1.8(1.3,2.5)$ \\
\hline Frequent & $0.6(0.1,0.5)$ & $0.2(0.0,0.5)$ & $0.5(0.2,0.9)$ \\
\hline \multicolumn{4}{|l|}{ Women } \\
\hline Lack of sexual interest & $33.7(28.9,38.6)$ & $24.2(21.9,26.6)$ & $30.1(27.9,32.3)$ \\
\hline Occasional & $11.8(8.6,15.2)$ & $8.2(6.7,9.7)$ & $8.3(7.1,9.7)$ \\
\hline Periodic & $15.9(12.3,19.8)$ & $10.6(9.0,12.4)$ & $13.1(11.6,14.8)$ \\
\hline Frequent & $6.0(3.8,8.8)$ & $5.3(4.2,6.7)$ & $8.4(7.2,9.8)$ \\
\hline Sex not pleasurable & $25.2(20.9,29.8)$ & $15.6(13.7,17.7)$ & $22.7(20.8,24.7)$ \\
\hline Occasional & $9.7(7.0,13.2)$ & $6.7(5.4,8.2)$ & $6.7(5.5,7.9)$ \\
\hline Periodic & $13.1(9.8,16.7)$ & $5.9(4.7,7.3)$ & $11.6(10.1,13.2)$ \\
\hline Frequent & $2.4(1.1,4.4)$ & $2.7(1.9,3.7)$ & $4.3(3.4,5.4)$ \\
\hline Inability to reach orgasm & $23.6(19.4,28.1)$ & $17.4(15.4,19.5)$ & $24.8(22.8,26.9)$ \\
\hline Occasional & $9.2(6.3,12.4)$ & $7.3(5.9,8.8)$ & $7.3(6.1,8.6)$ \\
\hline Periodic & $12.0(8.9,15.6)$ & $5.9(4.7,7.3)$ & $11.5(9.9,13.1)$ \\
\hline Frequent & $2.5(1.2,4.7)$ & $4.1(3.1,5.3)$ & $6.0(4.9,7.2)$ \\
\hline Lubrication difficulties & $20.3(16.3,24.6)$ & $20.3(18.1,22.7)$ & $16.8(15.0,18.6)$ \\
\hline Occasional & $5.9(3.8,8.8)$ & $6.7(5.3,8.2)$ & $3.8(2.9,4.8)$ \\
\hline Periodic & $7.8(5.3,10.9)$ & $7.4(6.0,8.9)$ & $8.0(6.8,9.4)$ \\
\hline Frequent & $6.6(4.2,9.4)$ & $6.3(5.0,7.8)$ & $5.0(3.9,6.1)$ \\
\hline Pain during sex & $15.3(12.1,18.7)$ & $7.6(6.3,8.9)$ & $11.7(10.4,13.2)$ \\
\hline Occasional & $4.0(2.4,6.0)$ & $3.3(2.5,4.3)$ & $3.2(2.5,4.0)$ \\
\hline Periodic & $8.6(6.3,11.5)$ & $2.5(1.7,3.2)$ & $5.3(4.4,6.3)$ \\
\hline Frequent & $2.8(1.7,3.8)$ & $1.8(1.1,2.5)$ & $3.2(2.4,4.0)$ \\
\hline
\end{tabular}

Based on reports from sexually active respondents. The percentage in the first row of each panel indicates the country/regional average of sexual problem. The difference between the regional average and the sum of the three levels of severity of sexual problem indicates the proportion who failed to specify the level of severity. All prevalences are adjusted according to the age distribution of the total of sexually active men or women in the UK. Northern Europe includes Austria (500 subjects), Belgium (500), Germany (1500) and Sweden (1500). Southern Europe includes France (1500), Italy (1500) and Spain (1500). possible reasons (from which they were to check all that applied). The reasons included attitudes and beliefs regarding the sexual problem and the patient-doctor relationship. All respondents were also asked During a routine office visit or consultation in the past 3 years, 'Has your physician asked you about possible sexual difficulties without you bringing it up first? (Yes/No) and 'Do you think a doctor should routinely ask patients about their sexual function? (Yes/No).

The categorization of household income as low, medium or high was based on the distribution of income in each country, to allow the comparison of nations with different absolute mean incomes.

The prevalence of a specific characteristic was calculated by dividing the number of cases by the corresponding population. The denominator for the calculation of the prevalence of sexual problem was the number of sexually active people. The prevalence estimates were age-standardized using the age distribution of the UK population, and are given with their 95\% $\mathrm{Cl}$ [16].

\section{RESULTS}

Overall, 11655 individuals were contacted, 2835 of whom were not eligible to participate. Of the 8820 eligible individuals, 1500 individuals (750 men and 750 women) completed the survey, for a response rate of $17 \%$. The study population was sampled stratified by age, with nearly equal numbers for each age decade (Table 1) and data were standardized for the age distribution of the UK population.

Most of the subjects were married or involved in an ongoing partnership (62.1\% of men and $57.1 \%$ of women; Table 1). Almost a third of the subjects were employed, about half were retired and more men (14.1\%) than women (7.6\%) were unemployed. More than 60\% of men and women said they were in good or excellent general health. Of men and women, $69 \%$ and $56 \%$ said that they had had sexual intercourse during the 12 months preceding the interview, while $27.1 \%$ of men and $18.8 \%$ of women engaged in sexual intercourse regularly (i.e. more than once a week).

Early ejaculation was the most common male sexual problem, and was reported by $20 \%$ of the sexually active men in the UK (13\% of all 


\begin{tabular}{|c|c|c|c|}
\hline Behaviour & UK & Northern Europe & Southern Europe \\
\hline \multicolumn{4}{|l|}{ Men } \\
\hline Talked to partner & $39.5(35.0,43.9)$ & $40.6(38.2,42.9)$ & $47.8(45.6,49.9)$ \\
\hline Talked to medical doctor & $26.0(22.2,30.2)$ & $15.5(13.7,17.3)$ & $21.2(19.5,23.0)$ \\
\hline Looked for information anonymously* & $12.5(9.7,15.8)$ & $11.9(10.3,13.5)$ & $14.0(12.6,15.6)$ \\
\hline Taken drugs/used devices or talked to pharmacist & $11.4(8.8,14.7)$ & $8.8(7.5,10.3)$ & $10.1(8.9,11.5)$ \\
\hline Talked to family member/friend & $5.3(3.5,7.7)$ & $7.1(5.9,8.5)$ & $11.4(10.1,12.8)$ \\
\hline Talked to psychiatrist, psychologist or marriage counsellor & $3.8(2.3,6.0)$ & $3.5(2.7,4.5)$ & $5.0(4.2,6.1)$ \\
\hline Talked to a clergy person or religious adviser & $1.0(0.3,2.4)$ & $0.4(0.2,0.9)$ & $1.2(0.8,1.8)$ \\
\hline Sought no help from a health professional & $72.9(68.8,76.9)$ & $83.1(81.1,84.8)$ & $76.6(74.6,78.3)$ \\
\hline No action taken & $48.0(42.1,51.2)$ & $47.1(45.4,50.3)$ & $39.4(37.4,41.6)$ \\
\hline \multicolumn{4}{|l|}{ Women } \\
\hline Talked to partner & $32.5(28.3,36.8)$ & $41.7(39.3,44.2)$ & $48.2(46.0,50.3)$ \\
\hline Talked to medical doctor & $16.7(13.4,20.2)$ & $20.1(18.2,22.2)$ & $24.1(22.3,26.0)$ \\
\hline Looked for information anonymously* & $10.6(8.1,13.8)$ & $15.0(13.3,16.8)$ & $12.8(11.3,14.2)$ \\
\hline Taken drugs/used devices or talked to pharmacist & $8.7(6.3,11.5)$ & $15.3(13.5,17.1)$ & $13.9(12.4,15.4)$ \\
\hline Talked to family member/friend & $9.3(6.8,12.2)$ & $12.4(10.9,14.1)$ & $14.9(13.4,16.4)$ \\
\hline Talked to psychiatrist, psychologist or marriage counsellor & $1.4(0.6,2.9)$ & $2.9(2.1,3.8)$ & $3.8(3.1,4.7)$ \\
\hline Talked to a clergy person or religious adviser & 0 & $1.4(0.9,2.1)$ & $2.5(1.9,3.3)$ \\
\hline Sought no help from a health professional & $82.3(78.5,85.6)$ & $76.8(74.7,78.8)$ & $74.3(72.4,76.1)$ \\
\hline No action taken & $57.7(53.2,62.1)$ & $40.4(37.9,42.8)$ & $37.9(35.8,39.9)$ \\
\hline
\end{tabular}

*In books/magazines or via telephone help-line/internet. Based on reports from respondents complaining of at least one sexual problem (regardless of severity). All prevalences are adjusted according to the age distribution of the total of sexually active men and women in the UK. Northern Europe includes Austria (500), Belgium (500), Germany (1500) and Sweden (1500). Southern Europe includes France (1500), Italy (1500) and Spain (1500).

sexually active men said they experienced this problem periodically or frequently; Table 2).

ED was the second most common male sexual problem in the UK sample, reported by $18 \%$ of sexually active men (13\% said they experienced this problem periodically or frequently). Overall, ED was reported more often among men in the UK than in other European regions, and the opposite pattern was found for pain during sex. Although the other sexual problems investigated, including early ejaculation, lack of sexual interest and inability to reach orgasm, were similarly prevalent in the UK and other parts of Europe, men in the UK tended to report experiencing them with greater frequency.

Lack of sexual interest (33.7\%), lack of pleasure in sex (25.2\%) and inability to reach orgasm (23.6\%) were the most common sexual problems reported by sexually active women in the UK (Table 2). About two-thirds of the women who reported each of these problems said that they experienced it frequently or periodically. The prevalence of these problems among sexually active women in the UK was similar to those seen in
Southern European region but somewhat higher than in Northern Europe. Although it was the least common sexual problem overall, pain during sex was reported more often among women in the UK than in other European regions.

The prevalence of selected help-seeking behaviour for sexual problems are summarized in Table 3 (values for respondents from other European regions are also included to allow comparisons). Of the UK respondents, $48.0 \%$ of men and $57.7 \%$ of women took no action (i.e. they did not seek any help or advice). More men (26.0\%) than women (16.7\%) reported talking to a medical doctor about their sexual problem(s); however, most men (72.9\%) and women (82.3\%) had not sought advice from a health professional. Overall, patterns of help-seeking behaviour were quite similar for men and women in the UK, and talking to their partner was the most common action taken by both men and women (39.5\% and 32.5\%, respectively).

Compared with the other European regions, men and women in the UK were most likely to take no action to seek help for any of the sexual problems surveyed. However, men were more likely to talk to a medical doctor in the UK than in other regions of Europe, while the opposite was true for women. Some less formal help-seeking behaviours were less common among men and women in the UK compared with the rest of Europe, including talking to the partner or family/friends.

Some of the factors that might be associated with seeking medical help for sexual problems are summarized in Table 4. Interestingly, the effects of having received at least some college education (compared with just primary school or less) on the likelihood of seeking medical help were quite different among men and women. The likelihood decreased significantly among men (odds ratio 0.4$)$, but seemed to increase among women (1.5). Erectile difficulties among men (6.0) and lubrication difficulties among women (2.4) both significantly increased the likelihood of seeking medical help.

General sexual attitudes that significantly increased the likelihood of seeking medical advice were, among men, thinking that a 
TABLE 4 Factors associated with seeking medical help for sexual problems by gender, UK, 2001-2002

\begin{tabular}{|c|c|c|}
\hline \multirow[b]{2}{*}{ Factor } & \multicolumn{2}{|l|}{ Odds ratio $(95 \% \mathrm{Cl})$} \\
\hline & Men & Women \\
\hline \multicolumn{3}{|l|}{ Age, years } \\
\hline $40-49$ & Ref & Ref \\
\hline $50-59$ & $0.81(0.28,2.35)$ & $1.39(0.57,3.40)$ \\
\hline $60-69$ & $0.65(0.24,1.77)$ & $0.35(0.10,1.32)$ \\
\hline $70-80$ & $0.51(0.17,1.57)$ & $0.26(0.05,1.43)$ \\
\hline \multicolumn{3}{|l|}{ Education } \\
\hline Primary school or less & Ref & Ref \\
\hline Secondary/high school & $1.04(0.25,4.41)$ & $0.64(0.33,1.25)$ \\
\hline At least some college & $0.46(0.21,0.98)^{*}$ & $1.45(0.64,3.30)$ \\
\hline High/medium household income (vs low) & $1.01(0.47,2.17)$ & $1.22(0.47,3.12)$ \\
\hline \multicolumn{3}{|l|}{ Sexual problems } \\
\hline Erectile difficulties & $6.0(2.93,12.24)+$ & \\
\hline Early ejaculation & $0.76(0.37,1.56)$ & \\
\hline Lack of sexual interest & $1.18(0.59,2.34)$ & $1.13(0.48,2.67)$ \\
\hline Inability to reach orgasm & & $1.43(0.66,3.11)$ \\
\hline Lubrication difficulties & & $2.38(1.04,5.43)^{*}$ \\
\hline \multicolumn{3}{|l|}{ General sexual attitudes } \\
\hline Have been asked by a doctor about possible sexual difficulties in a routine visit in the past 3 years & $1.12(0.31,4.09)$ & $1.15(0.27,4.83)$ \\
\hline Think a doctor should routinely ask patients about sexual function & $2.17(1.04,4.53)^{*}$ & $1.70(0.77,3.75)$ \\
\hline Very/somewhat dissatisfied with sexual function & $2.05(0.86,4.92)$ & $3.62(1.31,9.99)^{*}$ \\
\hline \multicolumn{3}{|l|}{ Belief that } \\
\hline Decreased ability to perform sexually would significantly affect self-esteem & $0.98(0.43,2.25)$ & $1.58(0.62,4.06)$ \\
\hline Sex is a extremely/very important part of overall life & $1.53(0.50,4.68)$ & $3.65(1.20,10.99)^{*}$ \\
\hline Think it is OK to use medical treatment for sexual problems & $1.97(0.71,5.49)$ & $2.96(0.60,14.69)$ \\
\hline Think that older people no longer want/have sex & $0.79(0.31,2.00)$ & $0.85(0.21,3.41)$ \\
\hline Belief in religion guiding sex & $2.06(0.92,4.66)$ & $1.22(0.51,2.92)$ \\
\hline
\end{tabular}

Odds ratios from logistic regression. Based on reports from respondents complaining of at least one sexual problem (regardless of severity). ${ }^{*} P=0.05 ;+P=0.001$.

doctor should routinely ask patients about their sexual function (odds ratio 2.2), and, among women, being very or somewhat dissatisfied with their sexual function (3.6) and the belief that sex is a very or extremely important part of overall life (3.7).

The most common reasons in the UK for not consulting a doctor about sexual problems were thinking it was not very serious or waiting for it to go away $(71.3 \%$ of men and $61.1 \%$ of women), belief that it is a normal part of ageing or being comfortable as he/she is ( $64.2 \%$ of men and $58.2 \%$ of women), and thinking it is not a medical problem or that a doctor would not be able to do much (48.6\% of men and $46.9 \%$ of women) (Table 5). These values were generally similar to those seen in other European regions, although a lack of perception of a sexual problem as a treatable medical condition was somewhat more common among men and women in the UK than in other parts of Europe. Few respondents in the UK cited lack of access to or affordability of medical care as a reason for not seeking medical help for their sexual problems (12.5\% of men and $13.5 \%$ of women); this reason was cited about twice as frequently by men and women in other parts of Europe.

Very few of the respondents in the UK had been asked by a doctor about possible sexual difficulties during a routine visit in the past 3 years (3.7\% of men and $4.2 \%$ of women). The figures were slightly higher in other parts of Europe, ranging from $6.1 \%$ among women in Southern Europe to $10.1 \%$ among women in Northern Europe. About a third (36.9\% of men and $29.2 \%$ of women) of all respondents in the UK thought that a doctor should routinely ask patients about their sexual function. This attitude was slightly more prevalent in other parts of Europe, ranging from $38.9 \%$ of women in Northern Europe to $48.6 \%$ of men in Southern Europe.

\section{DISCUSSION}

This is the first study to report data from the UK at population level on sexual behaviour and the prevalence of sexual dysfunction among middle-aged and older people, and in a manner that allows direct comparisons with other European regions.

A major strength of the GSSAB survey lies in its cross-national population sample and the use of a common method of data collection. Face-to-face interviews were avoided because they might embarrass people talking about private and sensitive issues, or induce respondents to give socially desirable answers [17]. We considered only the sexual problems that persisted with moderate to higher frequency as dysfunction [18]. It is therefore likely that the prevalence of sexual dysfunction is under-reported compared with studies that used more sensitive (and less specific) methods. 
TABLE 5 Attitudes, behaviours and beliefs about diagnosis and treatment of sexual problems by gender, 2001-2002

\begin{tabular}{|c|c|c|c|}
\hline Variable & UK & Northern Europe & Southern Europe \\
\hline \multicolumn{4}{|l|}{ Men } \\
\hline \multicolumn{4}{|l|}{ Reasons for not consulting a doctor about the experienced sexual problem* } \\
\hline Did not think it was very serious/Waiting if problem goes away & $71.3(67.1,75.3)$ & $68.9(66.5,71.1)$ & $51.5(49.4,53.7)$ \\
\hline Normal with ageing/I am comfortable the way I am & $64.2(61.2,67.1)$ & $75.6(72.5,78.2)$ & $62.3(59.2,65.2)$ \\
\hline Do not think it is a medical problem/Doctor cannot do much & $48.6(44.1,53.2)$ & $37.7(35.4,40.2)$ & $36.2(34.2,38.3)$ \\
\hline Not comfortable talking to a GP/GP is a close friend/GP wrong gender & $22.5(18.8,26.4)$ & $25.6(23.6,27.8)$ & $39.3(37.2,41.4)$ \\
\hline Do not have a regular physician/Doctor is expensive & $12.5(9.7,15.8)$ & $25.2(23.1,27.3)$ & $27.6(25.6,29.5)$ \\
\hline Doctor uneasy to talk about sex & $6.0(4.0,8.5)$ & $10.1(8.7,11.6)$ & $6.6(5.6,7.8)$ \\
\hline $\begin{array}{l}\text { Have been asked by a doctor about possible sexual difficulties in a routine visit } \\
\text { in the past } 3 \text { yearst }\end{array}$ & $3.7(2.2,5.8)$ & $8.2(6.9,9.6)$ & $7.4(6.3,8.5)$ \\
\hline $\begin{array}{l}\text { Think a doctor should routinely ask patients about their sexual functiont } \\
\text { Women }\end{array}$ & $36.9(32.6,41.4)$ & $47.3(44.9,49.8)$ & $48.6(46.4,50.7)$ \\
\hline \multicolumn{4}{|l|}{ Reasons for not consulting a doctor about the experienced sexual problem* } \\
\hline Did not think it was very serious/Waiting if problem goes away & $61.1(56.6,65.4)$ & $64.7(62.3,67.0)$ & $53.1(50.9,55.2)$ \\
\hline Normal with ageing/l am comfortable the way I am & $58.2(53.6,62.6)$ & $72.4(70.2,74.5)$ & $66.1(64.0,68.1)$ \\
\hline Do not think it is a medical problem/Doctor cannot do much & $46.9(42.3,51.3)$ & $38.4(36.0,40.8)$ & $34.7(32.7,36.8)$ \\
\hline Not comfortable talking to a GP/GP is a close friend/GP wrong gender & $24.5(20.8,28.6)$ & $25.5(23.4,27.7)$ & $44.2(42.1,46.3)$ \\
\hline Do not have a regular physician/doctor is expensive & $13.5(10.5,17.8)$ & $25.4(23.3,27.6)$ & $30.0(28.0,32.0)$ \\
\hline Doctor uneasy to talk about sex & $3.8(2.2,5.8)$ & $8.7(7.4,10.2)$ & $9.1(7.9,10.4)$ \\
\hline $\begin{array}{l}\text { Have been asked by a doctor about possible sexual difficulties in a routine visit } \\
\text { in the past } 3 \text { yearst }\end{array}$ & $4.2(2.5,6.3)$ & $10.1(8.7,11.6)$ & $6.1(5.1,7.2)$ \\
\hline Think a doctor should routinely ask patients about their sexual functiont & $29.2(25.3,33.5)$ & $38.9(36.5,41.3)$ & $39.6(37.5,41.7)$ \\
\hline
\end{tabular}

The response rate in the present study (17\%) was not high, but while it is true that low completion rates can serve as a signal for the possibility of systematic biases in sample coverage, it by no means guarantees or necessitates it. People are in general highly resistive to telephone interviewing and are likely to decline to participate, regardless of the subject matter. The prevalence of self-reported health conditions such as hypertension, diabetes and smoking in GSSAB (data not shown here) was consistent with published age- and gender-specific values [19-21], and the patterns of help-seeking behaviour are similar to those reported by a recent British study [22]. Thus we think that the reason for refusing to participate in the study was a general unwillingness to undergo a telephone interview, and that this is unlikely to have introduced a bias in the estimates of the prevalence of sexual behaviours and dysfunction. In general, we find that our estimates of prevalence are comparable to the published estimates for the UK. This suggests that we were not disproportionately recruiting a sample from those who suffer from sexual problems of one sort or another. It also appears to indicate that the study population was broadly representative of the UK population, whereas many of the published studies of sexual problems have tended to focus on specific subgroups of individuals who are most likely to experience such problems, such as patients attending a genitourinary medicine clinic, middle-aged women, or men who have had a prostatectomy $[11,13,23,24]$.

Our findings indicate that doctors in the UK (and in the rest of Europe) rarely ask patients about their sexual health during a routine consultation, even though this would be welcomed by a substantial proportion of men and women. This apparent reluctance to initiate a discussion about sexual functioning might be due, at least in part, to an acknowledged lack of undergraduate and postgraduate medical training in the management of sexual problems [25]. A recent study conducted among general practices in London concluded that sexual difficulties are highly prevalent among patients visiting GPs and, as also reported in our study population, many men and women are prepared to discuss these problems with a doctor [8].

Most published studies of the cost to the UK NHS of treatment for sexual problems have focused on the management of ED in men [26]. The total cost to the NHS of treating ED increased from £79 800 in 1997 to £257 984 in 2000, but the cost per patient decreased from $£ 368$ to $£ 286$ [26]. This indicates that the shift in prescribing responsibility from specialists to GPs, that has occurred since the introduction of effective oral treatment for ED in 1998, has resulted in improved costeffectiveness [27].

In conclusion, our results show that, in the UK, as in other European regions, sexual desire and activity are widespread among middle-aged and elderly men and women. The prevalence of sexual dysfunction is substantial, but few of the people who experience sexual difficulties seek medical help, perhaps because they do not perceive their condition as sufficiently 
severe, potentially treatable, or sufficiently upsetting. Appropriate educational programmes for patients and healthcare professionals might be required to enable a greater proportion of older adults to continue to enjoy a satisfying sexual life.

\section{ACKNOWLEDGEMENTS}

The authors acknowledge the contribution of their colleagues on the study's international Advisory Board: Gerald Brock (Canada), Jacques Buvat (France), Uwe Hartmann (Germany), Sae-Chul Kim (Korea), Rosie King (Australia), Edward Laumann (USA), Bernard Levinson (South Africa), Ken Marumo (Japan) and Ferruh Simsek (Turkey). Financial support: The Global Study of Sexual Attitudes and Behaviours was funded by Pfizer Inc.

\section{CONFLICT OF INTEREST}

Edson D. Moreira Jr, Alfredo Nicolosi and Clive Gingell are consultants for Pfizer Inc., and Dale B. Glasser is an employee and stock owner of Pfizer Inc.

\section{REFERENCES}

1 Deacon S, Minichiello V, Plummer D. Sexuality and older people: revisiting the assumptions. Educ Gerontol 1995; 21 : 497-513

2 Matthias RE, Lubben JE, Atchison KA, Schwietzer 0. Sexual activity and satisfaction among very old adults: results from a community-dwelling Medicare population survey. Gerontologist 1997; 37: 6-14

3 Gott M, Hinchliff S. How important is sex in later life? The views of older people. Soc Sci Med 2003; 56: 1617-28

4 Braun M, Wassmer G, Klotz T, Riefenrath B, Mathers M, Engelmann U. Epidemiology of erectile dysfunction: results of the 'Cologne Male Survey'. Int J Impot Res 2000; 12: 305-11

5 Nicolosi A, Moreira EDJr, Shirai M, Bin Mohd Tambi MI, Glasser DB. Epidemiology of erectile dysfunction in four countries: cross-national study of the prevalence and correlates of erectile dysfunction. Urology 2003; 61: 201-6

6 Blanker MH, Bosch JL, Groeneveld FP et al. Erectile and ejaculatory dysfunction in a community-based sample of men 50-78 years old: prevalence, concern, and relation to sexual activity. Urology 2001; 57: 763-8
7 Helgason AR, Adolfsson J, Dickman P et al. Sexual desire, erection, orgasm and ejaculatory functions and their importance to elderly Swedish men: a population-based study. Age Ageing 1996; 25: 285-91

8 Nazareth I, Boynton P, King M. Problems with sexual function in people attending London general practitioners. BMJ 2003; 327: 423-6

9 Dunn KM, Croft PR, Hackett GI. Sexual problems: a study of the prevalence and need for care in the general population. Fam Pract 1998; 15: 519-24

10 Moreira EDJr, Lisboa Lôbo CF, Villa M, Nicolosi A, Glasser DB. Prevalence and correlates of erectile dysfunction in Salvador, northeastern Brazil: a population-based study. Int J Impot Res 2002; 14 (Suppl. 2): S3-9

11 Osborn M, Hawton K, Gath D. Sexual dysfunction among middle-aged women in the community. BMJ 1988; 296: 95962

12 Barlow DH, Cardozo LD, Francis RM et al. Urogenital ageing and its effect on sexual health in older British women. Br J Obstet Gynecol 1997; 104: 8791

13 Kuh DL, Wadsworth M, Hardy R. Women's health in midlife: the influence of the menopause, social factors and health in earlier life. Br J Obstet Gynaecol 1977; 104: 923-33

14 Laumann EO, Nicolosi A, Glasser DB et al. for the GSSAB Investigators' Group. Sexual problems among women and men aged $40-80$ years: prevalence and correlates identified in the global study of sexual attitudes and behaviors. Int J Impot Res 2005; 17: 39-57

15 Nicolosi A, Laumann EO, Glasser DB et al. Sexual behavior and sexual problems after the age of 40: the Global Study of Sexual Attitudes and Behaviors (GSSAB). Urology 2004; 64: 991-7

16 Gardner MJ, Altman DG. Confidence intervals rather than $P$ value: estimation rather than hypothesis testing. BMJ 1987; 292: 746-50

17 ASCF Principal Investigators and Their Associates. Analysis of sexual behaviour in France (ACSF). A comparison between two modes of investigation: telephone survey and face-to-face survey. AIDS 1992; 6: 315-23

18 Moynihan R. The making of a disease: female sexual dysfunction. BMJ 2003; 326: $45-7$
19 Wolf-Maier K, Cooper RS, Banegas JR et al. Hypertension prevalence and blood pressure levels in 6 European countries, Canada, and the United States. JAMA 2003; 289: 2363-9

20 Gill GV, Ismail AA, Beeching NJ, Macfarlane SB, Bellis MA. Hidden diabetes in the UK: use of capturerecapture methods to estimate total prevalence of diabetes mellitus in an urban population. J R Soc Med 2003; 96: 328-32

21 Eurostat. Health statistics - key data on health 2002 - data 1970-2001

22 Mercer $\mathrm{CH}$, Fenton KA, Johnson AM et al. Sexual function problems and help seeking behaviour in Britain: national probability sample survey. BMJ 2003; 327: 426-7

23 Goldmeier D, Judd A, Schroeder K. Prevalence of sexual dysfunction in new heterosexual attenders at a central London genitourinary medicine clinic in 1998. Sex Transm Infect 2000; 76: 208-9

24 Bates TS, Wright MP, Gillatt DA. Prevalence and impact of incontinence and impotence following total prostatectomy assessed anonymously by the ICS-male questionnaire. Eur Urol 1998; 33: 165-9

25 Whitmore J. Problems with sexual function: training in psychosocial medicine is available for doctors. BMJ 2003; 327: 1109-10

26 Wilson EC, McKeen ES, Scuffham PA, Brown MC, Wylie K, Hackett G. The cost to the United Kingdom National Health Service of managing erectile dysfunction: the impact of sildenafil and prescribing restrictions. Pharmacoeconomics 2002; 20: 879-89

27 Ashton-Key M, Sadler M, Walmsley B, Holmes S, Randall S, Cummings $\mathrm{MH}$. UK Department of Health guidance on prescribing for impotence following the introduction of sildenafil: potential to contain costs in the average health authority district. Pharmacoeconomics 2002; 20: 839-46

Correspondence: Edson D. Moreira, Unit of Epidemiology and Biostatistics, Oswald Cruz Foundation, Rua Waldemar Falcão 121, Salvador, Bahia, Brazil, 40.295-001. e-mail: edson@cpqgm.fiocruz.br

Abbreviations: ED, erectile dysfunction; GSSAB, Global Study of Sexual Attitudes and Behaviours. 